Article

\title{
Sorption of Methylene Blue for Studying the Specific Surface Properties of Biomass Carbohydrates
}

\author{
Tatiana Skripkina ${ }^{1, *}$, Ekaterina Podgorbunskikh ${ }^{1}\left(\mathbb{D}\right.$, Aleksey Bychkov ${ }^{1,2}{ }^{\oplus}$ and \\ Oleg Lomovsky ${ }^{1}$ \\ 1 Institute of Solid State Chemistry and Mechanochemistry SB RAS, Kutateladze 18, \\ 630128 Novosibirsk, Russia; podgorbunskikh@solid.nsc.ru (E.P.); bychkov_a@solid.nsc.ru (A.B.); \\ lomov@solid.nsc.ru (O.L.) \\ 2 Faculty of Business, Novosibirsk State Technical University, 20 Prospekt K. Marksa, \\ 630073 Novosibirsk, Russia \\ * Correspondence: skripkinats@solid.nsc.ru
}

Received: 20 October 2020; Accepted: 17 November 2020; Published: 20 November 2020

\begin{abstract}
The surface area is an important parameter in setting any biorefining technology. The aim of this study was to investigate the applicability of sorption of methylene blue to characterize the surface of the main biomass carbohydrates: $\alpha$-cellulose, sigmacell cellulose, natural gum, $\beta$-glucan, and starch. The morphology of particles of the model objects was studied by scanning electron microscopy. Nitrogen adsorption isotherms demonstrate that the selected carbohydrates are macroporous adsorbents. The monolayer capacities, the energy constants of the Brunauer-Emmett-Teller (BET) equation, and specific surface areas were calculated using the BET theory, the comparative method proposed by Gregg and Sing, and the Harkins-Jura method. The method of methylene blue sorption onto biomass carbohydrates was adapted and mastered. It was demonstrated that sorption of methylene blue proceeds successfully in ethanol, thus facilitating surface characterization for carbohydrates that are either soluble in water or regain water. It was found that the methylene blue sorption values correlate with specific surface area determined by nitrogen adsorption/desorption and calculated from the granulometric data. As a result of electrostatic attraction, the presence of ion-exchanged groups on the analyte surface has a stronger effect on binding of methylene blue than the surface area does. Sorption of methylene blue can be used in addition to gas adsorption/desorption to assess the accessibility of carbohydrate surface for binding large molecules.
\end{abstract}

Keywords: surface area; cellulose; starch; $\beta$-glucan; natural gum

\section{Introduction}

Plant raw materials consist of various polymers, for example, cellulose, lignin, hemicelluloses, and minor components: starch and gum. Not all of them undergo heterogeneous reactions with the yield of target products. Cellulose was chosen as the most common plant polysaccharide, $\beta$-glucan was chosen as a representative of the second most important component of cell walls-hemicelluloses, konjac gum, and potato starch - as plant raw material polysaccharides that are important for the food industry $[1,2]$. The biomass surface area accessible for reactions at the solid/liquid interface plays a significant role [3-5]. Thus, during heterogeneous enzymatic hydrolysis of cellulose, the initial rate of the reaction (the interaction between enzymes on a solid substrate surface) directly depends on the number of accessible sites (the accessible surface area). In this connection, most classical studies on biorefinery place a special focus on pretreatment of plant biomass, which is somehow related to particle size reduction [6,7]. In turn, this changes the surface area of the interface between the solid substrate and liquid reagents [8-10]. Further assessment of biomass reactivity often uses the concept of specific 
surface area (SSA) [11-13]. The conventional methods employed to evaluate this parameter neither take into account the features of the surface of biomass-derived materials, nor illustrate whether the surface is accessible for molecules larger than gas molecules. For example, in the method of thermal gas desorption using the Brunauer-Emmett-Teller equation (BET method), a number of assumptions are made [11]. It is assumed that the surface of solids is energetically homogeneous (adsorption centers are the same), but lignocellulose biomass is a macroporous material, which leads to measurement error [14]. However, even with modifications taken into account, gas desorption methods cannot correctly estimate the surface area available for enzymes [15]. In particular, the catalytic core of Trichoderma reesei endoglucanase has a size of about $4-5 \mathrm{~nm}$, which makes the surface of pores with a smaller diameter inaccessible [16].

Sorption of cellulose-cleaving high-molecular-weight compounds (dyes or proteins), whose size and shape are rather similar to those of cellulose-cleaving enzymes, is a rather promising trend in studying surface properties [17-19]. The method of dye sorption allows one to more accurately assess the surface area of solids accessible to the reactants compared with low-temperature desorption of gas (nitrogen or steam), as a dye molecule is larger than a gas molecule. The application of this method is limited by solubility in water or water regain by the biomass, whereas water is used as a solvent in the existing dye sorption procedures [20-22].

Methylene blue is a common cationic dye widely used in the textile and paper industries. The dye forms ionic bonds with the substrates owing to its cationic (basic) nature. Dye sorption is widely used to characterize the surface area of solids, because adsorbate concentration can be determined spectrophotometrically, which significantly simplifies the experiment [23,24]. This method allows more precise assessment of the surface area of polysaccharides accessible to reactants compared with low-temperature adsorption/desorption of gases, because a dye molecule is larger than a gas molecule. Methylene blue is considered the dye most commonly used for this purpose [25]. The application of methylene blue to characterize the surface area for activated carbon has been reported previously (test methods for fibrous activated carbon) [26]. As methylene blue is soluble in ethanol, it would be interesting to adapt the procedure of methylene blue sorption from an ethanol solution to characterize the surface of biomass polysaccharides. This would make it possible to use the new method for assessing the changes in properties of the biomass surface.

This study was aimed at adapting the methylene blue sorption technique to analyze the surface properties of biomass carbohydrates. The dye sorption data were compared to those obtained by analyzing particle size and shape and using the method of thermal desorption of gas. The proposed approach allows one to improve the procedure for studying the surface properties and evaluate the accessibility of the carbohydrate surface for binding large molecules.

\section{Materials and Methods}

\subsection{Materials}

The following natural carbohydrates were used as study objects: $\alpha$-cellulose (Sigma Aldrich, Moscow, Russia), microcrystalline cellulose Sigmacell Cellulose (Sigma Aldrich, Moscow, Russia), konjac gum (Foodchem International Corporation, Shanghai, China), $\beta$-glucan (Megazyme Ltd., Co. Wicklow, Ireland), potato starch (State Standard GOST R 53876-2010, ZAO Garnec, Vladimir, Russia), and corn starch (State Standard GOST 32159-2013, ZAO Garnec, Vladimir, Russia). Methylene blue dye in the $\mathrm{C}_{16} \mathrm{H}_{18} \mathrm{~N}_{3} \mathrm{SCl} \cdot 3 \mathrm{H}_{2} \mathrm{O}$ form (reagent grade, OJSC Shostka Chemical Reagents Plant, Shostka, Ukraine) was used.

\subsection{Matrix Structure and Morphology Analysis}

The micrographs of the samples were recorded on a Hitachi TM-1000 scanning electron microscope (Hitachi, Tokyo, Japan). A gold coating was deposited on the sample surface to remove the accumulated charge using a JFC-1600 Auto Fine Coater (Jeol, Tokyo, Japan) (ion current $30 \mathrm{~mA}$, spray time $1 \mathrm{~min}$ ). 
The granulometric analysis was conducted by laser diffraction scattering (LDS) on a Microsizer 201 particle size analyzer (VA Instalt, St. Petersburg, Russia) equipped with an ultrasonic disperser. Water was used as a dispersed phase for $\alpha$-cellulose, sigmacell cellulose, and starch; ethanol was used for $\beta$-glucan and konjac gum. The specific surface area (SSA) was estimated from the particle size distribution using Equation (1):

$$
S A A=6 l \rho
$$

where $l$ is the particle size determined by granulometric analysis and $\rho$ is the density of the biomass (assumed to be equal to $1.2 \mathrm{~g} / \mathrm{cm}^{3}$ ).

The nitrogen sorption/desorption curves were plotted on a Sorptometer $\mathrm{M}$ specific surface area analyzer (ZAO Catakon, Novosibirsk, Russia) at a desorption temperature of $-5{ }^{\circ} \mathrm{C}$, thermostat temperature of $45^{\circ} \mathrm{C}$, adsorber temperature of $-196^{\circ} \mathrm{C}$, heating time of $600 \mathrm{~min}$, and heating rate of $200{ }^{\circ} \mathrm{C} / \mathrm{min}$. The selected thermostat temperature and heating rate ensure the achievement of the appropriate desorption temperature during the experiment. Immediately before the experiment, degassing was carried out for $4 \mathrm{~h}$ at $105^{\circ} \mathrm{C}$ for cellulose and sigmacell cellulose; and $6 \mathrm{~h}$ at $60^{\circ} \mathrm{C}$ for $\beta$-glucane, konjac gum, and starch samples. The desorption temperature $\left(-5^{\circ} \mathrm{C}\right)$ used for measuring the surface area of lignocellulosic substrates was determined experimentally from the data on full nitrogen desorption from the adsorbent surface (unlike the desorption temperature conventionally used for analyzing inorganic solid bodies $\left(-50^{\circ} \mathrm{C}\right)$ ).

Specific surface area was determined in the initial area of adsorption isotherms, in the region before the initiation of capillary condensation (usually measured at $P / P_{0}=0.05-0.35$ ). In order to determine the monolayer capacity, $a_{\mathrm{m}}$, the Brunauer-Emmett-Teller (BET) equation was written in a linear form (2):

$$
\frac{P / P_{0}}{a\left(1-P / P_{0}\right)}=\frac{1}{a_{\mathrm{m}} C}+\frac{C-1}{a_{\mathrm{m}} C} \times \frac{P}{P_{0}}
$$

where $P$ is the partial pressure of the adsorbate; $P_{0}$ is the saturated vapor pressure of the adsorbate at a melting point of liquid nitrogen $\left(-196^{\circ} \mathrm{C}\right)$; $a$ is the amount of adsorbed gas per $\mathrm{g}$ of the sample, $\mathrm{mL} / \mathrm{g}$; and $C$ is the dimensionless energy constant.

The specific surface area was calculated using Equation (3):

$$
S A A=a_{\mathrm{m}} \times N_{\mathrm{A}} \times \omega
$$

where $a_{\mathrm{m}}$ is the monolayer capacity, $\mathrm{mol} / \mathrm{g} ; N_{A}$ is the Avogadro's number; and $\omega$ is the area occupied by an adsorbate molecule in the filled monolayer on the adsorbent surface (for $\mathrm{N}_{2}$, this value is $0.162 \mathrm{~nm}^{2}$ ).

The comparative method proposed by Gregg and Sing is based on relationship (4) [27]:

$$
a_{\mathrm{s}}=\frac{a}{a_{0.4}}
$$

where $a_{0.4}$ is adsorption at partial pressure $P / P_{0}=0.4$.

\subsection{Methylene Blue Sorption and Spectrophotometric Analysis}

Experiments on methylene blue sorption. The sample under study $(1 \mathrm{~g})$ was added to $100 \mathrm{~mL}$ of methylene blue solution in ethanol $(0.1 \mathrm{~g} / \mathrm{L})$. The mixture was thermostated on a plate shaker thermostat for $96 \mathrm{~h}$ at a shaking frequency of $130 \mathrm{rpm}$ and temperature of $25^{\circ} \mathrm{C}$. Sample preparation prior to spectrophotometric analysis involved centrifugation of a solution and 2-, 5-, and 10-fold dilution of the resulting samples with ethanol. Solutions having concentrations of $0.15,0.1,0.075,0.05$, and $0.0375 \mathrm{~g} / \mathrm{L}$ were prepared to plot the calibration curves showing the absorbance of solutions in water and ethanol. The calibration curves were plotted using freshly prepared solutions prior to every new measurement to avoid dye adsorption onto laboratory glassware during storage. One can find an example of the calibration plot on Figure S1 of Supplementary Materials. Spectrophotometric analysis was conducted 
on a UV/VIS spectrophotometer SF-2000 (LOMO Ltd., St. Petersburg, Russia) using polystyrene cells relative to water in the case of water samples and ethanol for ethanol solutions.

\section{Results and Discussion}

Figure 1 shows micrographs of selected samples.

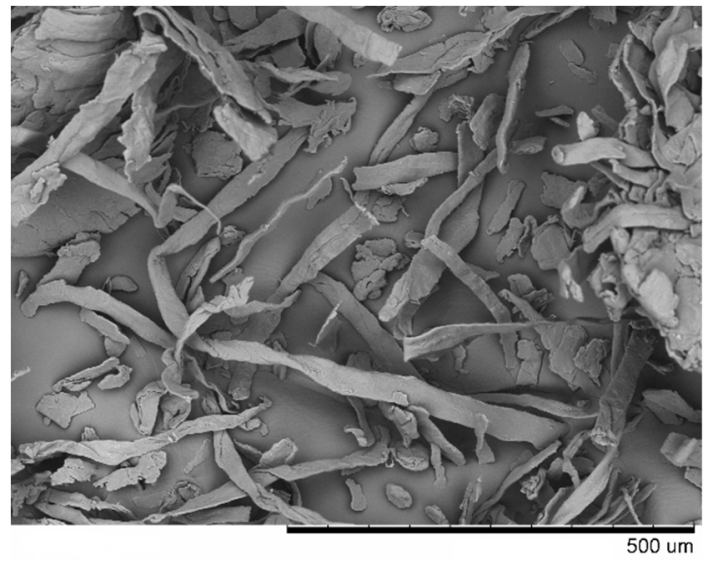

(a)

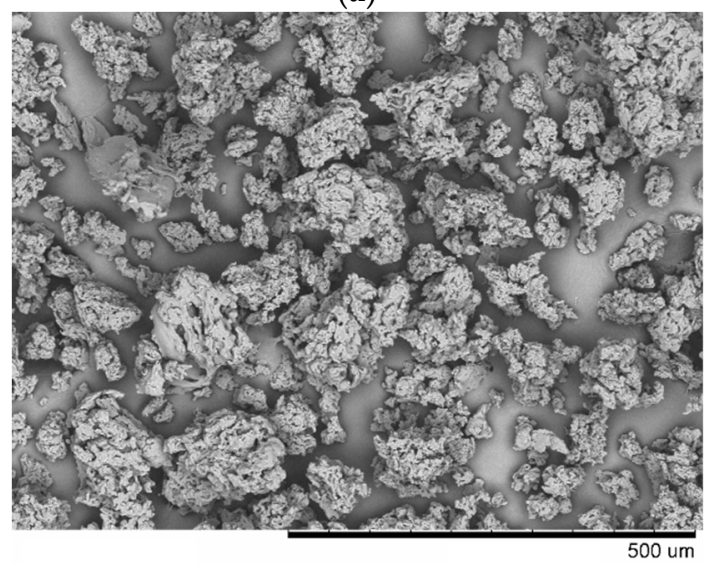

(c)

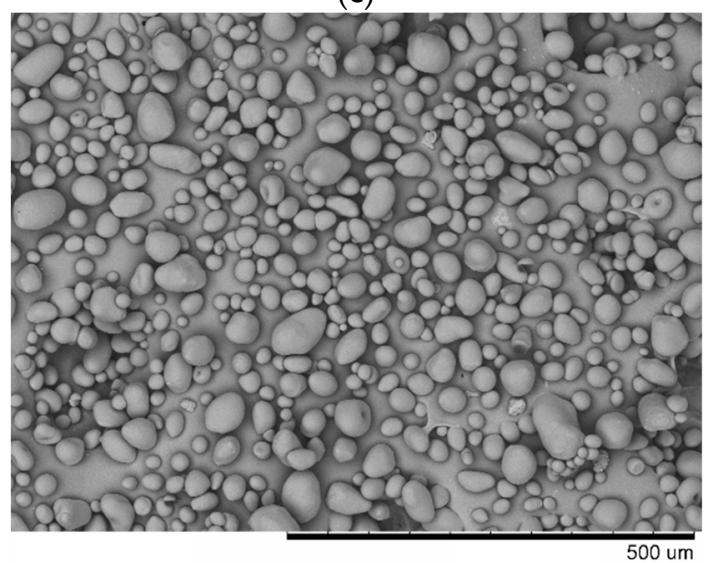

(e)

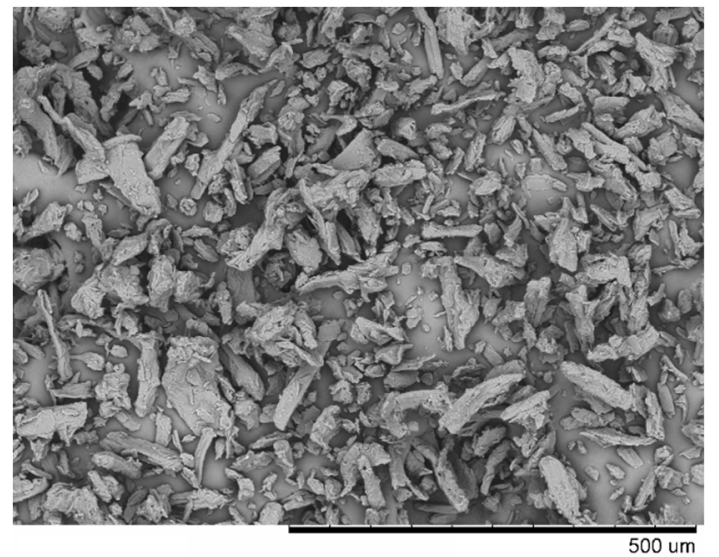

(b)

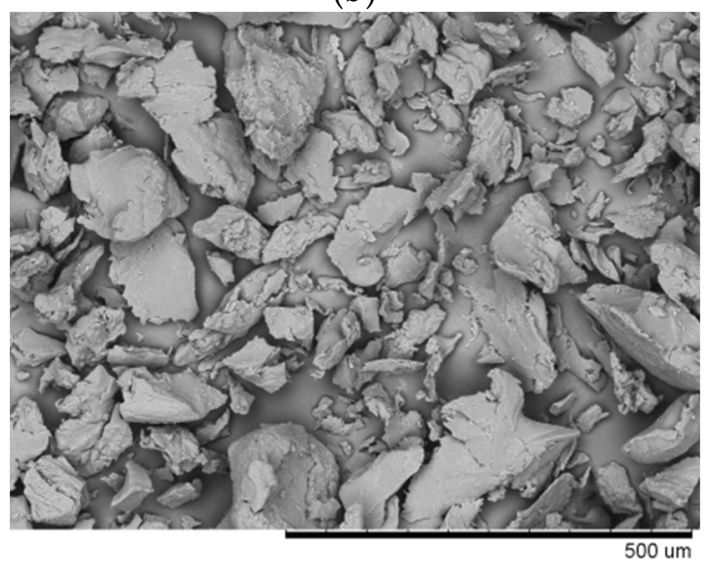

(d)

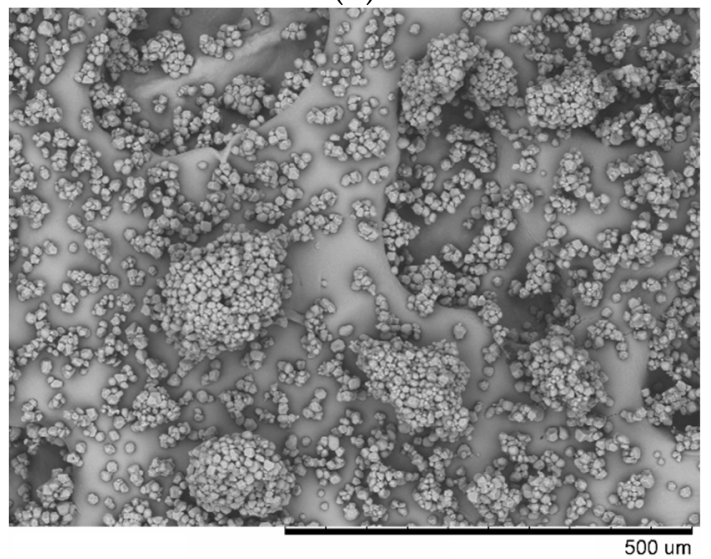

(f)

Figure 1. Scanning electron microscopy (SEM) images of study objects: (a) $\alpha$-cellulose, (b) sigmacell cellulose, (c) $\beta$-glucan, (d) konjac gum, (e) potato starch, and (f) corn starch.

In the micrographs of $\alpha$-cellulose, one can clearly identify fibrils up to $500 \mu \mathrm{m}$ long and $<10 \mu \mathrm{m}$ wide, as well as their agglomerates (Figure 1a). Sigmacell cellulose (Figure 1b) consists of oblong particles up to $150 \mu \mathrm{m}$ long and up to $50 \mu \mathrm{m}$ wide. The particle surface is very heterogeneous and 
contains protruding fibrils. $\beta$-Glucan (Figure 1c) consists of agglomerates sized up to $200-300 \mu \mathrm{m}$ made of particles $\sim 20 \mu \mathrm{m}$ in size. Particles within the agglomerates are packed rather loosely, and a large number of pores and tunnels are formed. Konjac gum (Figure 1d) consists of irregularly shaped angular particles that significantly vary in their size. The maximum linear size is $200 \mu \mathrm{m}$. No pores can be seen, and the particle surface is rather rough. Starch granules have a spherical and elliptical shape (Figure 1e) and a diameter of 20-50 $\mu \mathrm{m}$.

The shapes of the isotherms of nitrogen adsorption onto biomass carbohydrates indicated that the main plant biomass components are macroporous adsorbents. In the case of konjac gum, the surface appears to be smoother with no obvious pores on the particle surface (Figure 1d), which is confirmed by adsorption isotherms. It can be seen that the isotherm curves for konjac gum (or sorption/desorption curves) are significantly lower than the curves of adsorption isotherms of porous polymers (Figure 2). The surface properties of starch are poorly analyzable using thermal desorption of nitrogen (Figure 2e,f), which is confirmed by the smooth surface and round shape of particles of starch (Figure 1e,f), and by the almost complete absence in the literature of data on gas sorption on the surface of untreated starch This fact was repeatedly tested in parallel experiments conducted for starch obtained from various sources in a broad range of sample exposure parameters and desorption temperatures.

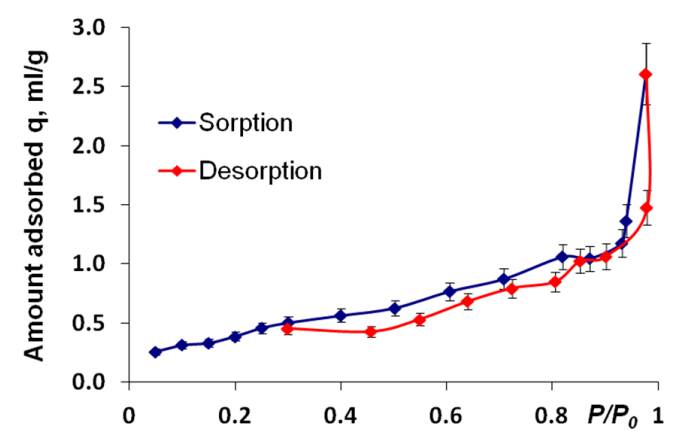

(a)

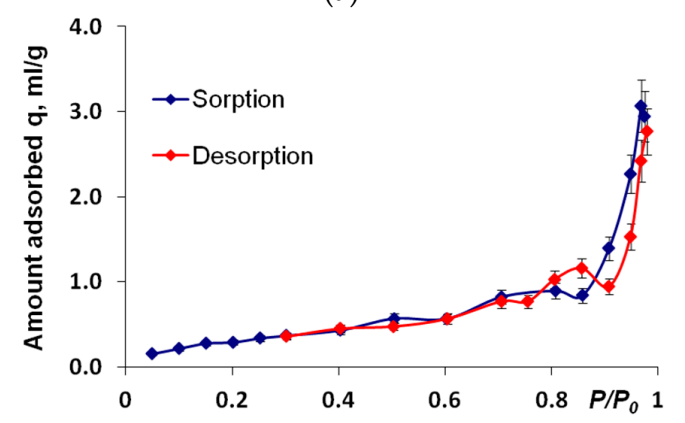

(c)

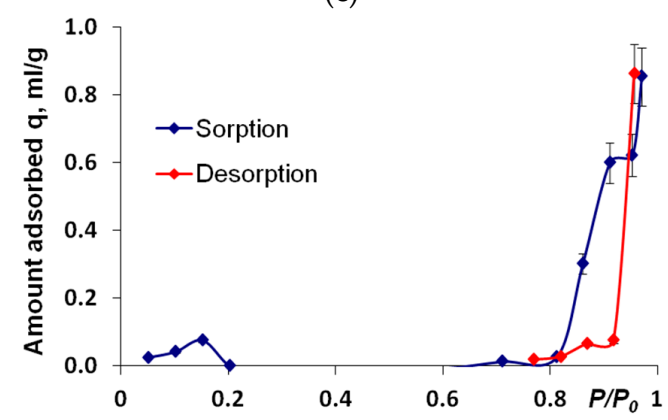

(e)

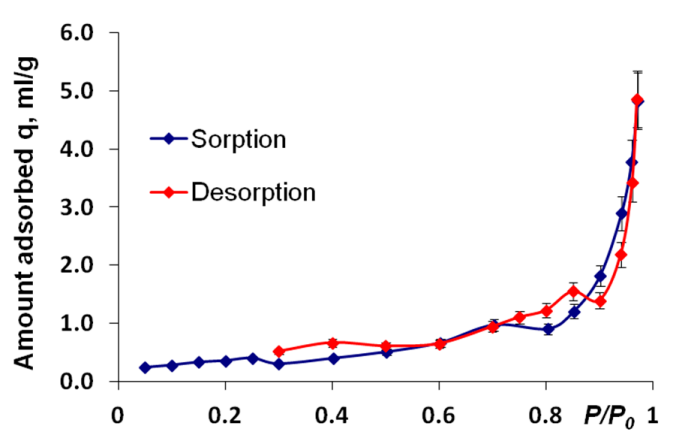

(b)

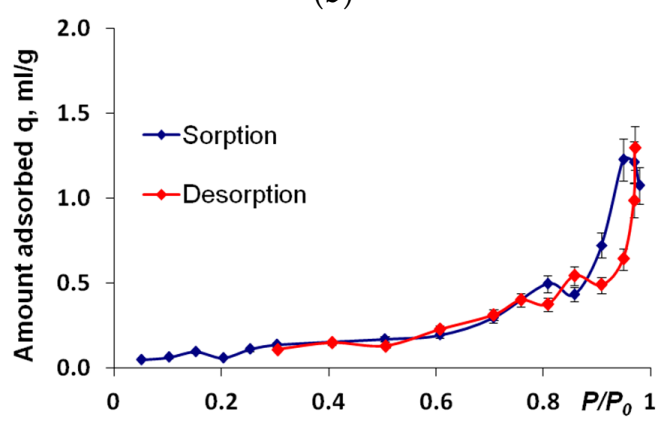

(d)

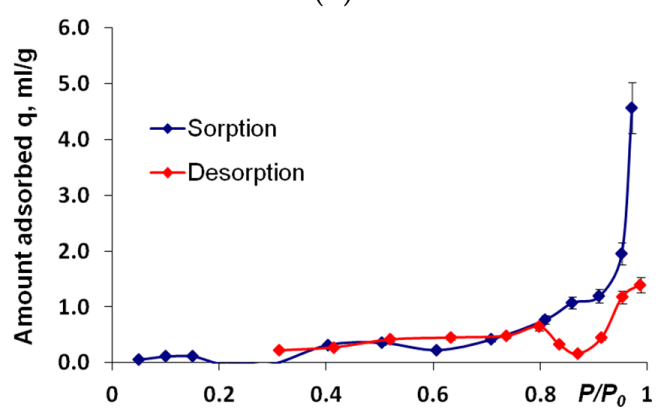

(f)

Figure 2. The isotherms of nitrogen adsorption onto biomass carbohydrates: (a) $\alpha$-cellulose, (b) sigmacell cellulose, (c) $\beta$-glucan, (d) konjac gum, (e) potato starch, and (f) corn starch. 
The results obtained for the main biomass carbohydrates (cellulose and $\beta$-glucan) using the single-point and multipoint BET methods demonstrate that this technique is characterized by high convergence and low relative error ( 15-20\%) (Table 1). The $C_{\mathrm{BET}}$ constant represents the energy of adsorption in the first layer and characterizes the adsorbent/adsorbate interactions. The $C_{\mathrm{BET}}$ values being close to 100 indicate that the adsorbent/adsorbate interaction is rather strong and the surface is filled with gas molecules to a significant extent.

Table 1. Specific surface area (SSA) and surface characteristics of the isolated carbohydrates calculated using the data on thermal desorption of nitrogen. BET, Brunauer-Emmett-Teller.

\begin{tabular}{|c|c|c|c|c|c|}
\hline \multirow[b]{2}{*}{ Sample } & \multicolumn{3}{|c|}{ BET Method } & \multirow{2}{*}{$\begin{array}{l}\text { SSA (The Method } \\
\text { Proposed by Gregg } \\
\text { and Sing), } \mathrm{m}^{2} / \mathrm{g}\end{array}$} & \multirow{2}{*}{$\begin{array}{l}\text { SSA (The Method } \\
\text { Proposed by } \\
\text { Harkins-Jura), m²/g }\end{array}$} \\
\hline & $\begin{array}{l}\text { Energy Constant in the } \\
\text { BET Equation } C_{\mathrm{BET}}\end{array}$ & $\begin{array}{l}\text { SSA (Single-Point } \\
\text { BET Method), } \mathrm{m}^{2} / \mathrm{g}\end{array}$ & $\begin{array}{l}\text { SSA (Multipoint BET } \\
\text { Method), } \mathrm{m}^{2} / \mathrm{g}\end{array}$ & & \\
\hline$\alpha$-cellulose & 89 & $1.4 \pm 0.1$ & $1.6 \pm 0.1$ & $2.3 \pm 0.3$ & $2.2 \pm 0.3$ \\
\hline $\begin{array}{l}\text { Sigmacell } \\
\text { cellulose }\end{array}$ & 92 & $1.4 \pm 0.1$ & $1.40 \pm 0.02$ & $2.3 \pm 0.9$ & $2.1 \pm 0.8$ \\
\hline$\beta$-glucan & 19 & $1.4 \pm 0.1$ & $1.4 \pm 0.1$ & $2.3 \pm 0.2$ & $2.2 \pm 0.2$ \\
\hline Konjac gum & 27 & 0.2 & 0.3 & 0.5 & 0.5 \\
\hline
\end{tabular}

The low $C_{\mathrm{BET}}$ values for starch are indicative of low adsorption energy and looser packing of nitrogen on the surface. In this case, a correction for the specific surface area was introduced: $\omega=0.22-0.28 \mathrm{~nm}^{2}$ for organic polymers [28]. For potato and corn starch, the corrected specific surface area ranges between 0.9 and $1.3 \mathrm{~m}^{2} / \mathrm{g}$.

The effective surface area was determined according to sorption of methylene blue dye. Biomass polysaccharides, either soluble in water or retaining it, are stable in ethanol. Therefore, an important stage of method adaptation was to conduct the experiment using ethanol as a solvent for methylene blue. Methylene blue solutions in water (Figure 3, curve $a$ ) and ethanol (Figure 3, curve $b$ ) were prepared. Pigment concentration was $0.05 \mathrm{~g} / \mathrm{L}$. The $\mathrm{pH}$ values of water and ethanol solutions of methylene blue were 4.4 and 5.7, respectively.

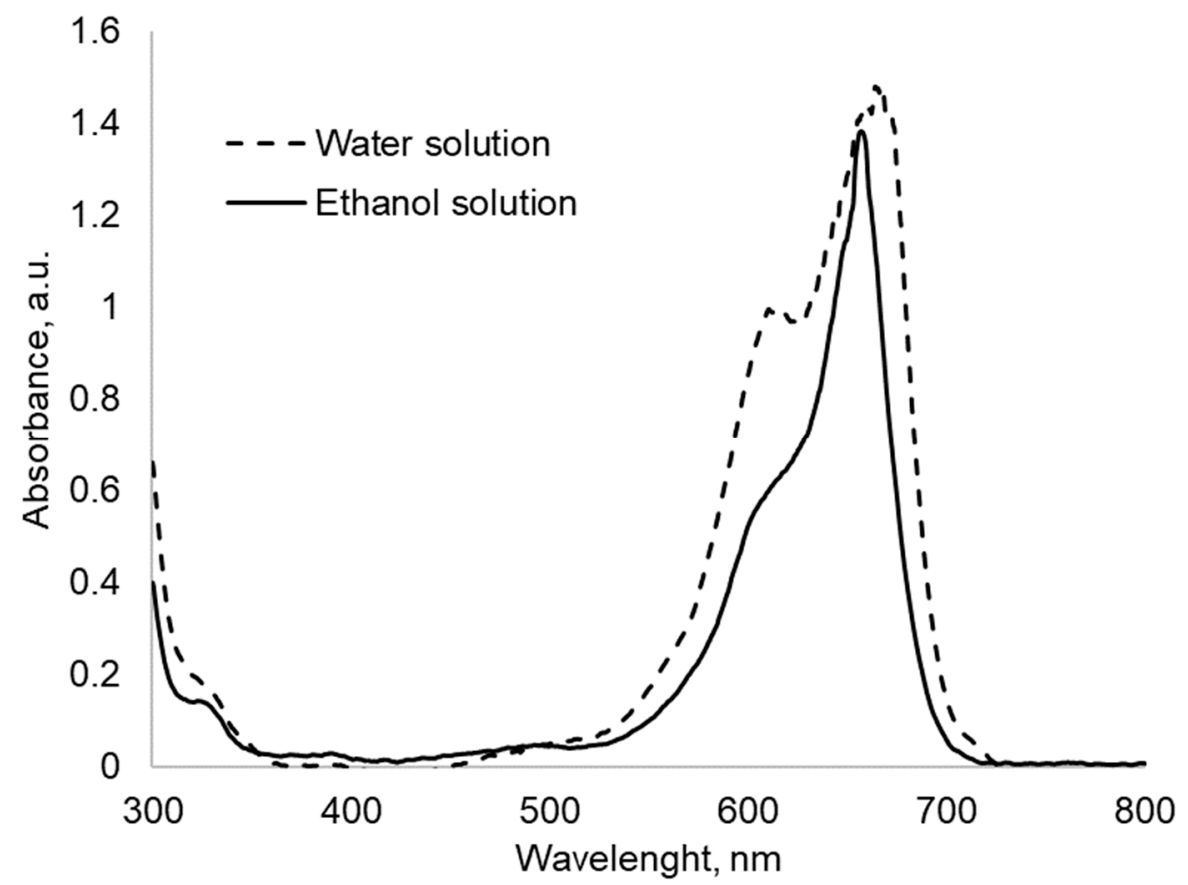

Figure 3. Absorption spectra of $0.01 \mathrm{~g} / \mathrm{L}$ of methylene blue solution.

The absorption spectra of methylene blue in water and ethanol are generally similar. The absorption spectrum of methylene blue solution in water has maxima at wavelengths of $\lambda=612$ and $665 \mathrm{~nm}$. 
The absorption spectrum of methylene blue solution in ethanol has a less defin peak at $612 \mathrm{~nm}$ and an absorption maximum at $660 \mathrm{~nm}$. The peak at $612 \mathrm{~nm}$ is characterized for dimer form of the dye, so in ethanol, methylene blue presents mainly in monomer form. As some of the carbohydrates swell in water and the spectrum of methylene blue in ethanol has been shown to be similar to that in water, experiments on the sorption of methylene blue on carbohydrates of biomass were carried out in ethanol solution. The $\mathrm{pH}$ values of ethanol solutions of methylene blue with the addition of $\alpha$-cellulose, sigmacell cellulose, konjac gum, $\beta$-glucan, and potato starch were 5.7, 5.3, 4.8, 5.1, and 5.2, respectively.

Figure 4 shows an example of the kinetics of sorption of methylene blue onto sigmacell cellulose in ethanol. The $30 \mathrm{~h}$ adsorption value was the highest for the sigmacell cellulose and $\beta$-glucan; for the other polysaccharides, the adsorption values were rather low and were achieved very quickly (Figure S2). The values of sorption were calculated from the optical density of the solutions at $\lambda=660 \mathrm{~nm}$ after $96 \mathrm{~h}$ of sorption of methylene blue. One can find the raw data on the values of the optical density in Tables S1 and S2 of Supplementary Materials. Table 2 summarizes the findings on sorption of methylene blue from ethanol onto biomass carbohydrates and the data obtained by nitrogen adsorption/desorption (the BET method), the average particle size, and the surface area estimated from particle size distribution (Equation (1)).

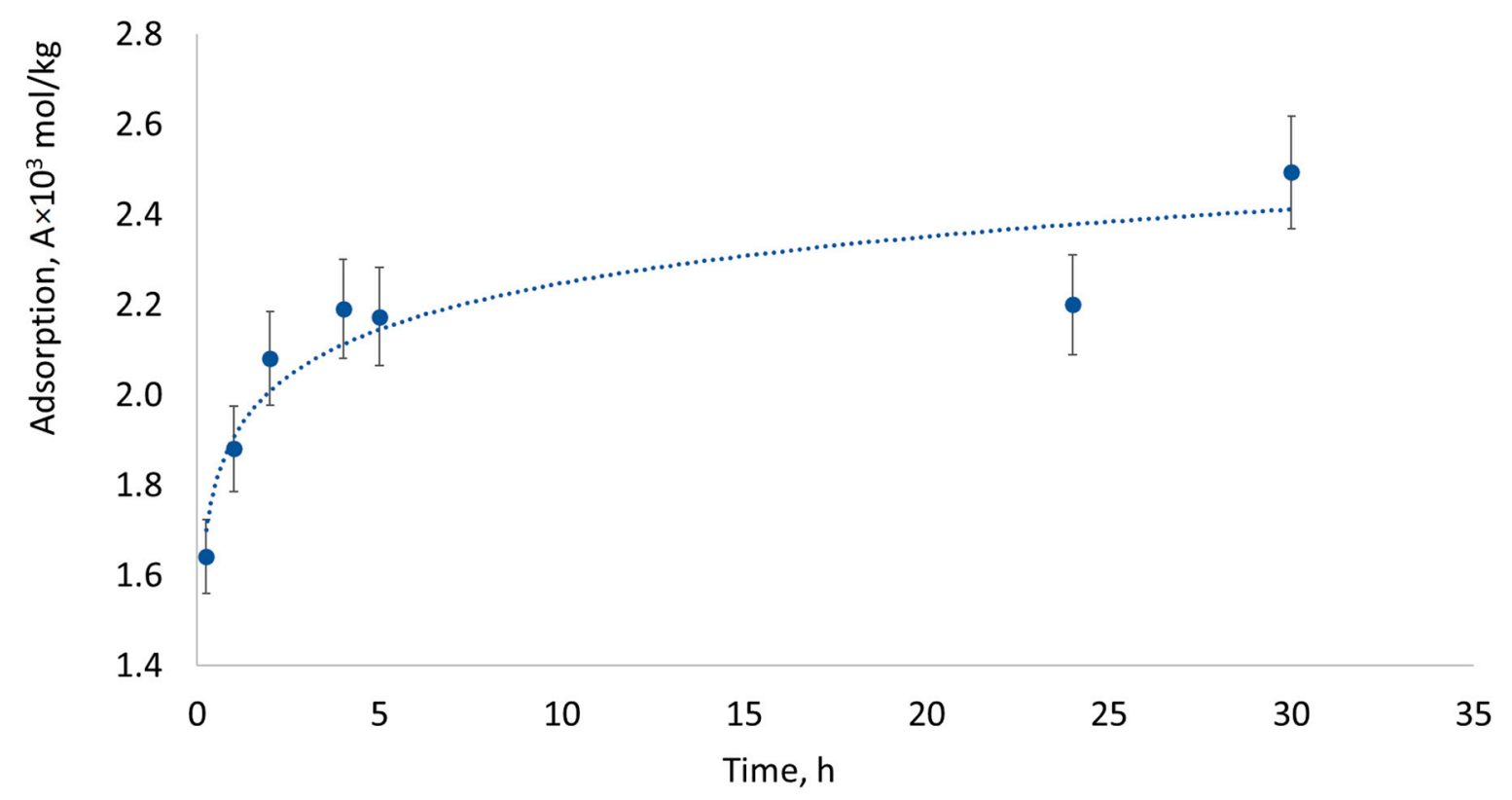

Figure 4. The isothermal kinetics of sorption of methylene blue onto sigmacell cellulose in ethanol.

Table 2. Sorption of methylene blue onto biomass carbohydrates and comparison of the results to the data obtained using other methods.

\begin{tabular}{ccccc}
\hline Sample & $\begin{array}{c}\text { Sorption, } \mathbf{A} \times \mathbf{~ 1 0}^{\mathbf{3}} \\
\mathbf{m m o l} / \mathbf{g}\end{array}$ & $\begin{array}{c}\text { SSA (Multipoint } \\
\text { BET Method), } \mathbf{~ m}^{\mathbf{2}} \mathbf{g}\end{array}$ & $\begin{array}{c}\text { Average Particle } \\
\text { Size, } \boldsymbol{\mu m}\end{array}$ & $\begin{array}{c}\text { SSA Determined } \\
\text { from Particle } \\
\text { Distribution, } \mathbf{~ m}^{\mathbf{2}} / \mathbf{g}\end{array}$ \\
\hline -cellulose & $0.10 \pm 0.04$ & $1.6 \pm 0.1$ & $75.6 \pm 0.3$ & $0.10 \pm 0.01$ \\
Sigmacell cellulose & $9.7 \pm 0.4$ & $1.40 \pm 0.02$ & $35.6 \pm 0.9$ & $0.20 \pm 0.01$ \\
Konjac gum & $1.10 \pm 0.09$ & 0.3 & $104.1 \pm 0.9$ & $0.07 \pm 0.01$ \\
$\beta$-glucan & $4.0 \pm 0.1$ & $1.4 \pm 0.1$ & $106.6 \pm 1.7$ & $0.07 \pm 0.01$ \\
Potato starch & $0.30 \pm 0.07$ & 0.8 & $42.3 \pm 0.6$ & $0.17 \pm 0.02$ \\
\hline
\end{tabular}

The resulting sorption values partially agree with the surface characteristics obtained using the gas adsorption/desorption method. The greatest differences are observed for the data for cellulose. According to granulometric analysis, sigmacell cellulose particles are twofold smaller than $\alpha$-cellulose ones, which is consistent with the particle morphology studied using the micrographs of the sample. 
The fact that surface areas determined using the gas adsorption/desorption method are almost identical, while particles' sizes differ significantly, demonstrates that $\alpha$-cellulose has a more developed surface because of its roughness or a large number of pores. The fact that $\alpha$-cellulose almost does not bind methylene blue may indicate that $\alpha$-cellulose has small pores inaccessible for the dye molecule. This can also be proved by comparing these data to starch. Although its particles are 1.7-fold larger, starch is three times more efficient in binding the dye.

The significant dye-binding ability revealed for sigmacell cellulose is attributed to the physicochemical properties of its surface. An electrical double layer is formed on the sigmacell cellulose surface in polar solvents because of ionization of carboxyl groups and is responsible for the negative surface charge of sigmacell cellulose particles [29]. The negatively charged groups increase the binding of methylene blue as a result of electrostatic attraction [30]. Therefore, it can be inferred that the presence of ion-exchanging groups on the analyte surface exhibits a greater effect on binding of methylene blue than the surface area does. This conclusion is consistent with the numerous studies focused on sorption capacity of various biomass-derived materials with respect to methylene blue [31]. Hence, Husseien et al. [32] reported that the sorption capacity of carbonized corn stalk was higher than that of pristine corn stalk. They attributed this effect to aggregation of small pores to form larger pores permeable for methylene blue molecules. However, new acid groups were supposed to be formed under the conditions being used [33], which would have affected the binding of methylene blue more significantly. Uddin et al. [34] demonstrated that sorption capacity of tea waste with respect to methylene blue was enhanced with decreasing sorbent surface charge as the $\mathrm{pH}$ of the medium increased. Hence, it is fair to say that surface characterization experiments can be conducted at a low $\mathrm{pH}$ to reduce the effect of chemical adsorption.

In the absence of negative surface charge, it is interesting to use sorption of methylene blue dye for assessing surface accessibility for binding large molecules. The ratio between sorption of methylene blue onto $\beta$-glucan and its sorption onto konjac gum is $\sim 4: 1$; the ratio between the specific surface areas calculated using the BET method is also 4:1. This may indicate that both samples contain no pores that can incorporate a nitrogen molecule, but are too small to accommodate a dye molecule.

\section{Conclusions}

A study to adapt and master the procedure used for sorption of methylene blue onto selected biomass-derived carbohydrates to analyze the surface of biomass carbohydrates for evaluation of the accessibility of the carbohydrate surface for binding large molecules was conducted.

It was demonstrated that sorption of methylene blue successfully runs in ethanol, thus facilitating surface characterization for carbohydrates that are either soluble in water or exhibit water regain. Sorption of methylene blue is one of the convenient methods used to characterize the carbohydrate surface. However, not all the data obtained using this method can be interpreted unambiguously. The optimal way to apply this method is to use it for comparative studies of the surface of various samples.

In general, the dye sorption method can be used in addition to gas adsorption/desorption to evaluate the accessibility of the carbohydrate surface for binding large molecules. However, when applying this method, one should either take into account the surface charge of particles under study or minimize it by conducting the experiments at $\mathrm{pH}$ below 7 .

It would be interesting to further develop the method by analyzing the surface of the native biomass. Sorption of methylene blue will be useful for determining the percentage of the feedstock surface corresponding to substances carrying electronegative functional groups (e.g., lignin).

Supplementary Materials: The following are available online at http://www.mdpi.com/2079-6412/10/11/1115/s1, Figure S1: A calibration plot for determining methylene blue concentration in ethanol, $\lambda=660 \mathrm{~nm}$, Figure S2: The isothermal kinetics of sorption of methylene blue onto biomass carbohydrates in ethanol, Table S1: The raw data on the values of the optical density of the solutions at $\lambda=660 \mathrm{~nm}$ after 96 hours of sorption of methylene blue, Table S2: The calculation of the values of the sorption of methylene blue (MB) from the data of Table S1. 
Author Contributions: Conceptualization, A.B. and O.L.; methodology, T.S. and E.P.; validation, A.B. and O.L.; formal analysis, T.S. and E.P.; investigation, T.S. and E.P.; resources, A.B. and O.L.; data curation, A.B.; writing — original draft preparation, T.S.; writing—-review and editing, T.S. and E.P.; visualization, T.S. and E.P.; supervision, O.L.; project administration, A.B. and O.L.; funding acquisition, A.B. and O.L. All authors have read and agreed to the published version of the manuscript.

Funding: The study was funded by the Russian Foundation for Basic Research (project No. 19-03-00065).

Conflicts of Interest: The authors declare no conflict of interest.

\section{References}

1. Huang, Q.; Liu, Z.; Pei, Y.; Li, J.; Li, B. Gelation behaviors of the konjac gum from different origins: A. guripingensis and A. rivirei. Food Hydrocoll. 2021, 111, 106152. [CrossRef]

2. Semeijn, C.; Buwalda, P.L. Potato Starch. In Starch in Food; Elsevier: Amsterdam, The Netherlands, 2018; pp. 353-372.

3. Kashcheyeva, E.I.; Gladysheva, E.K.; Skiba, E.A.; Budaeva, V.V. A study of properties and enzymatic hydrolysis of bacterial cellulose. Cellulose 2019, 26, 2255-2265. [CrossRef]

4. Lu, M.; Li, J.; Han, L.; Xiao, W. An aggregated understanding of cellulase adsorption and hydrolysis for ball-milled cellulose. Bioresour. Technol. 2019, 273, 1-7. [CrossRef] [PubMed]

5. Sinitsyn, A.P.; Gusakov, A.V.; Vlasenko, E.Y. Effect of structural and physico-chemical features of cellulosic substrates on the efficiency of enzymatic hydrolysis. Appl. Biochem. Biotechnol. 1991, 30, 43-59. [CrossRef]

6. Sapozhnikov, A.N.; Kopylova, A.V.; Krainova, Y.O.; Krainov, S.A. The prospects of using spinach in flour and bakery products. Proc. Vor. State Univ. Eng. Technol. 2019, 80, 234-239. [CrossRef]

7. Cova, C.M.; Luque, R. Advances in mechanochemical processes for biomass valorization. BMC Chem. Eng. 2019, 1, 16. [CrossRef]

8. Nill, J.; Karuna, N.; Jeoh, T. The impact of kinetic parameters on cellulose hydrolysis rates. Process Biochem. 2018, 74, 108-117. [CrossRef]

9. Kim, D. Physico-chemical conversion of lignocellulose: Inhibitor effects and detoxification strategies: A mini review. Molecules 2018, 23, 309. [CrossRef]

10. Fang, Z. Pretreatment Techniques for Biofuels and Biorefineries; Springer: Berlin/Heidelberg, Germany, 2013.

11. Brunauer, S.; Emmett, P.H.; Teller, E. Adsorption of gases in multimolecular layers. J. Am. Chem. Soc. 1938, 60, 309-319. [CrossRef]

12. Staudt, P.B.; Kechinski, C.P.; Tessaro, I.C.; Marczak, L.D.F.; de Soares, R.P.; Cardozo, N.S.M. A new method for predicting sorption isotherms at different temperatures using the BET model. J. Food Eng. 2013, 114, 139-145. [CrossRef]

13. Zhang, D.; Luo, R. Modifying the BET model for accurately determining specific surface area and surface energy components of aggregates. Constr. Build. Mater. 2018, 175, 653-663. [CrossRef]

14. Thompson, D.N.; Chen, H.-C.; Grethlein, H.E. Comparison of pretreatment methods on the basis of available surface area. Bioresour. Technol. 1992, 39, 155-163. [CrossRef]

15. Podgorbunskikh, E.M.; Bychkov, A.L.; Lomovsky, O.I. Determination of surface accessibility of the cellulose substrate according to enzyme sorption. Polymers 2019, 11, 1201. [CrossRef] [PubMed]

16. Zhao, X.; Zhang, L.; Liu, D. Biomass recalcitrance. Part I: The chemical compositions and physical structures affecting the enzymatic hydrolysis of lignocellulose. Biofuels Bioprod. Biorefining 2012, 6, 465-482. [CrossRef]

17. Toumi, K.; Bergaoui, M.; Khalfaoui, M.; Benguerba, Y.; Erto, A.; Dotto, G.L.; Amrane, A.; Nacef, S.; Ernst, B. Computational study of acid blue 80 dye adsorption on low cost agricultural algerian olive cake waste: Statistical mechanics and molecular dynamic simulations. J. Mol. Liq. 2018, 271, 40-50. [CrossRef]

18. Hong, J.; Ye, X.; Zhang, Y.-H.P. Quantitative determination of cellulose accessibility to cellulase based on adsorption of a nonhydrolytic fusion protein containing CBM and GFP with its applications. Langmuir 2007, 23, 12535-12540. [CrossRef]

19. Wang, Q.Q.; He, Z.; Zhu, Z.; Zhang, Y.-H.P.; Ni, Y.; Luo, X.L.; Zhu, J.Y. Evaluations of cellulose accessibilities of lignocelluloses by solute exclusion and protein adsorption techniques. Biotechnol. Bioeng. 2012, 109, 381-389. [CrossRef]

20. Bulut, Y.; Aydın, H. A kinetics and thermodynamics study of methylene blue adsorption on wheat shells. Desalination 2006, 194, 259-267. [CrossRef] 
21. Wang, Y.; Li, Y.; Li, H.; Zheng, H.; Du, Q. Equilibrium, kinetic and thermodynamic studies on methylene blue adsorption by konjac glucomannan/activated carbon aerogel. J. Polym. Environ. 2019, 27, 1342-1351. [CrossRef]

22. Alver, E.; Metin, A.Ü.; Brouers, F. Methylene blue adsorption on magnetic alginate/rice husk bio-composite. Int. J. Biol. Macromol. 2020, 154, 104-113. [CrossRef]

23. Dev, S.; Singh, M. Metallic sulfide nanoparticles anchored graphene oxide: Synthesis, characterization and reduction of methylene blue to leuco methylene blue in aqueous mixtures. J. Phys. Chem. Solids 2020, 139, 109335. [CrossRef]

24. Hussin, M.H.; Pohan, N.A.; Garba, Z.N.; Kassim, M.J.; Rahim, A.A.; Brosse, N.; Yemloul, M.; Fazita, M.R.N.; Haafiz, M.K.M. Physicochemical of microcrystalline cellulose from oil palm fronds as potential methylene blue adsorbents. Int. J. Biol. Macromol. 2016, 92, 11-19. [CrossRef] [PubMed]

25. Chen, L.; Batchelor-McAuley, C.; Rasche, B.; Johnston, C.; Hindle, N.; Compton, R.G. Surface area measurements of graphene and graphene oxide samples: Dopamine adsorption as a complement or alternative to methylene blue? Appl. Mater. Today 2020, 18, 100506. [CrossRef]

26. International Organization for Standardization. Test Methods for Fibrous Activated Carbon; ISO 21340:2017; International organization for standardization: Geneve, Switzerland, 2017; p. 34.

27. Gregg, S.J.; Sing, K.S.W. Adsorption, surface area and porosity, 2nd ed.; Academic Press: London, UK, 1982.

28. Karnaukhov, A. Improvement of methods for surface area determinations. J. Colloid Interface Sci. 1985, 103, 311-320. [CrossRef]

29. Van de Steeg, H.G.M.; de Keizer, A.; Stuart, M.A.C.; Bijsterbosch, B.H. Adsorption of cationic amylopectin on microcrystalline cellulose. Colloids Surfaces A Physicochem. Eng. Asp. 1993, 70, 77-89. [CrossRef]

30. Rafatullah, M.; Sulaiman, O.; Hashim, R.; Ahmad, A. Adsorption of methylene blue on low-cost adsorbents: A review. J. Hazard. Mater. 2010, 177, 70-80. [CrossRef]

31. Özer, D.; Dursun, G.; Özer, A. Methylene blue adsorption from aqueous solution by dehydrated peanut hull. J. Hazard. Mater. 2007, 144, 171-179. [CrossRef]

32. Husseien, M.; Amer, A.A.; El-Maghraby, A.; Hamedallah, N. A comprehensive characterization of corn stalk and study of carbonized corn stalk in dye and gas oil sorption. J. Anal. Appl. Pyrolysis 2009, 86, 360-363. [CrossRef]

33. Xiao, L.-P.; Shi, Z.-J.; Xu, F.; Sun, R.-C. Hydrothermal carbonization of lignocellulosic biomass. Bioresour. Technol. 2012, 118, 619-623. [CrossRef]

34. Uddin, M.T.; Islam, M.A.; Mahmud, S.; Rukanuzzaman, M. Adsorptive removal of methylene blue by tea waste. J. Hazard. Mater. 2009, 164, 53-60. [CrossRef]

Publisher's Note: MDPI stays neutral with regard to jurisdictional claims in published maps and institutional affiliations.

(C) 2020 by the authors. Licensee MDPI, Basel, Switzerland. This article is an open access article distributed under the terms and conditions of the Creative Commons Attribution (CC BY) license (http://creativecommons.org/licenses/by/4.0/). 